\title{
Loss of Chromosome 9p
}

National Cancer Institute

\section{Source}

National Cancer Institute. Loss of Chromosome 9p. NCI Thesaurus. Code C36636.

A cytogenetic abnormality that refers to the loss of all or part of the short arm of chromosome 9 (9p). 